\title{
Modified Chaihu Shugan Powder for Functional Dyspepsia: Meta-Analysis for Randomized Controlled Trial
}

\author{
Nan Yang, Xuehua Jiang, ${ }^{1}$ Xuelan Qiu, ${ }^{1}$ Zhiqiang Hu, ${ }^{1}$ Ling Wang, ${ }^{1}$ and Minxian Song ${ }^{2}$ \\ ${ }^{1}$ Department of Clinical Pharmacy \& Pharmacy Administration, West China Pharmacy School, Sichuan University, \\ No. 17 Section 3 Renmin Nanlu, Chengdu, Sichuan 610041, China \\ ${ }^{2}$ School of Pharmacy, Jiangxi University of Traditional Chinese Medicine, No. 18, Yunwan Road, Wanli District, \\ Nanchang, Jiangxi 330004, China \\ Correspondence should be addressed to Xuehua Jiang; jxh1013@vip.163.com
}

Received 23 January 2013; Revised 4 April 2013; Accepted 11 April 2013

Academic Editor: Zhaoxiang Bian

Copyright (C) 2013 Nan Yang et al. This is an open access article distributed under the Creative Commons Attribution License, which permits unrestricted use, distribution, and reproduction in any medium, provided the original work is properly cited.

Context. Modified Chaihu Shugan powder (MCSP) is a popular traditional Chinese herbal formula for functional dyspepsia, which is revised from Chaihu Shugan San and recorded in a medical classic works of China. However, its role and effect in treating functional dyspepsia have not been well established. Objective. To assess the effect and safety of modified Chaihu Shugan powder for functional dyspepsia. Methods. We searched the published and unpublished studies up to August 2012. Only RCTs of modified Chaihu Shugan powder with or without prokinetic drugs versus prokinetic drugs in the patients diagnosed with functional dyspepsia were included. Results. Twenty-two clinical trials involving 1998 participants were included. There were evidences that modified Chaihu Shugan powder ( $R R=1.20,95 \%$, CI 1.14 to 1.27 ) and modified Chaihu Shugan powder plus prokinetic drugs $(\mathrm{RR}=1.18,95 \%, \mathrm{CI} 1.11$ to 1.25$)$ were significantly better treatment options than prokinetic drugs alone in improving symptoms. No serious adverse events were described in the included trials. Conclusions. This meta-analysis showed that modified Chaihu Shugan powder alone or in combination with prokinetic drugs might be more effective than prokinetic drugs alone. However, with poor methodological quality, all the included trials were at high risk of bias. Further large-scale high-quality trials are required for assessment.

\section{Introduction}

1.1. Rationale. Functional dyspepsia (FD), namely, functional gastrointestinal disorders or nonulcer dyspepsia, refers to symptoms centered in the upper abdominal region in absence of organic disease, such as epigastric pain, early satiety, fullness, belching, nausea, and vomiting [1-3]. It is a highly prevalent disorder. With influence of the definition applied, the global prevalence of FD had varied between $11.5 \%$ and $45 \%$ [4-6]. Although it is not a life-threatening condition, a number of out-patient studies suggested that FD markedly impaired patients' work and quality of life and laid a significant economic burden to the healthcare system [7-9]. Multiple factors, like motility abnormality, visceral hypersensitivity, psychosocial factors, excess secretion of gastric acid, duodenal acidity, helicobacter pylori, environment, diet, postinfectious factors, and genetics, were likely involved, but the pathogenesis of FD remains obscure [2, $6,10,11]$. For this reason, no single medicine is effective for all patients with FD. In the area of medical therapy, traditional Chinese medicine (TCM) plays an important part, besides prokinetics, antacids, $\mathrm{H}_{2}$-receptor antagonists, proton pump inhibitors, helicobacter pylori eradication, and antidepressants [12]. It was reported that at least one-third the US population used some form of TCM on a routine basis [13].

Chaihu Shugan San (CSS) is a classical and effective prescription recorded in a medical classic, Jingyue Quanshu also known as Jingyue's Complete Works, written in Ming Dynasty (1368-1644 year) of China, which has been used to improve some symptoms similar to FD by soothing liver, regulating qi, and relieving pain according to TCM theory. CSS are composed of Chinese Thorowax, Rhizoma Cyperi, Szechwan Lovage Rhizome, Pericarpium Citri Reticulatae, 
TABLE 1: Inclusion and exclusion for the selected studies.

\begin{tabular}{ll}
\hline Inclusion criteria & Exclusion criteria \\
\hline $\begin{array}{l}\text { The patients diagnosed with FD according to Rome II [25], } \\
\text { Rome III [26] consensus, or functional dyspepsia traditional } \\
\text { Chinese medicine diagnosis standard [16] }\end{array}$ & $\begin{array}{l}\text { Compared with other TCMs or control group combined with } \\
\text { acid-suppressive drugs, eradication of } H . \text { pylori, } \\
\text { fundus-relaxing drugs, and 5-HT }\end{array}$ receptor antagonists \\
\hline Control group with prokinetic drugs & $\begin{array}{l}\text { Successful treatment without measuring in terms of illness } \\
\text { severity scores or the intensity of individual symptoms }\end{array}$ \\
\hline Clearly outlined criteria for successful treatment & Course of treatment $\leq 2$ weeks \\
\hline Random allocation & \\
\hline
\end{tabular}

Fructus Aurantii, white peony root, and licorice. As we know every formula of TCM is an organic whole. A basic structure of formulas includes monarch, minister, assistant, and guide herbal medicines. According to TCM theory, so long as monarch herbal medicines and combination relationship of a classical prescription do not change, there is no change in the main clinical indications of the prescription [14]. In the procedure of TCM treatment, nearly all of the clinical prescriptions are modified by classic formulas [15]. In the prescription of CSS, Chinese Thorowax as monarch herbal medicine plays a principal role in therapeutic effect; Rhizoma Cyperi and Szechwan Lovage Rhizome are minister herbal medicine increasing the effect of Chinese Thorowax; Pericarpium Citri Reticulatae, Fructus Aurantii, and white peony root are used to harmonize the interaction between the ingredients; as a guide herbal medicine, licorice could guide the ingredients to the lesions. In the light of TCM theory, MSCP added Chinese Angelica or Radix Curcumae to the FD patients with qi stagnation and blood stasis, Cape Jasmine Fruit or Radix Scutellariae to the FD patients with transformation of depressed liver qi into fire, and Fructus Lycii or Radix Adenophorae to the FD patients with liver yin deficiency based on CSS [14]. Therefore, MCSP is now a popular traditional Chinese herbal formula for improving some symptoms similar to FD and recommended by functional dyspepsia traditional Chinese medicine diagnosis standard (2001 edition) [16].

The Study showed that MCSP could significantly increase propulsive rate of the small intestine $(77.16 \pm 3.42 \%)$ and decrease the residual amount of the pigment in the stomach in the rats [17]. Study from Qiu et al. suggested that ferulic acid and meranzin hydrate found in MCSP had the significant effect on promoting gastrointestinal motility in rats [18]. Saikosaponin (main activity of Chinese Thorowax) has antiinflammatory activity and raised the painful threshold value [19]. Fructus Aurantii can significantly inhibit the spontaneous movement of isolated duodenum from rabbits and reduce the contraction force which presents concentrationresponse relationship [20]. Zhu et al's study proved that Cyperus Rotundus can delay gastric emptying, protecting gastric mucosa and reduce incidents of ulcer in the model of rats' gastric ulcer [21]. White Peony root can reduce internal high sensitivity and regulate the function of brain-gut axis $[22,23]$. Animal studies have proved that Pericarpium Citri Reticulatae and licorice root promoted gastric emptying and small intestinal vermiculation and protected gastric mucosa [24].
1.2. Objectives. Evidence that clearly demonstrates effect and safety of MCSP has not yet been systematically studied. In this study, we evaluated the effects of MCSP in monotherapy or in combination with other prokinetic agents on FD through a rigorous systematic review and meta-analysis of randomized trial.

\section{Methods}

2.1. Eligibility Criteria. To make sure of the validity, applicability, and comprehensiveness, we specified the eligibility of inclusion and exclusion criteria for the review (Table 1).

2.2. Information Sources. We searched the following electronic database: Cochrane Library (issue to August 2012), MEDLINE (1995 to August 2012), EMBASE (1995 to August 2012), SCI database (Science Citation Index Expanded), CNKI Database (China Knowledge Resource Integrated Database, 1979 to August 2012), Wanfang Data (1998 to August 2012), VIP Information (1985 to August 2012), CBMDisc (Chinese Biology Medical disc, August 2012), and Chinese Clinical Trials Registry (issue to August 2012). We also screened the relevant trials and identified review listed in the references. We restricted the language of publications to English and Chinese.

2.3. Search Strategy. We used the Boolean logic search for the databases as follows: (modified chaihu shugan ${ }^{*} \mathrm{OR}$ chaihu shugan * OR chai hu shu gan * OR Bupleurum Soothing* ${ }^{*}$ ) and (functional dyspepsia OR nonulcer dyspepsia OR functional gastrointestinal disorders OR dyspepsia).

2.4. Study Selection. Two reviewers (N. Yang and X. Qiu) independently screened the information contained in the title, abstract, key words, and description of each searched paper according to the inclusion and exclusion criteria. Any difference during assessment between the two reviewers was discussed or resolved by a third dependent reviewer (X. Jiang).

2.5. Data Collection Process. We developed a data extraction sheet for the included study. To avoid bias in the data abstraction, two reviewers (X. Qiu and Z. Hu) independently abstracted the data from the papers and compared the results. Disagreements were resolved by discussion between the two reviews; if no agreements could be reached, it was resolved by the third dependent reviewer (X. Jiang). 


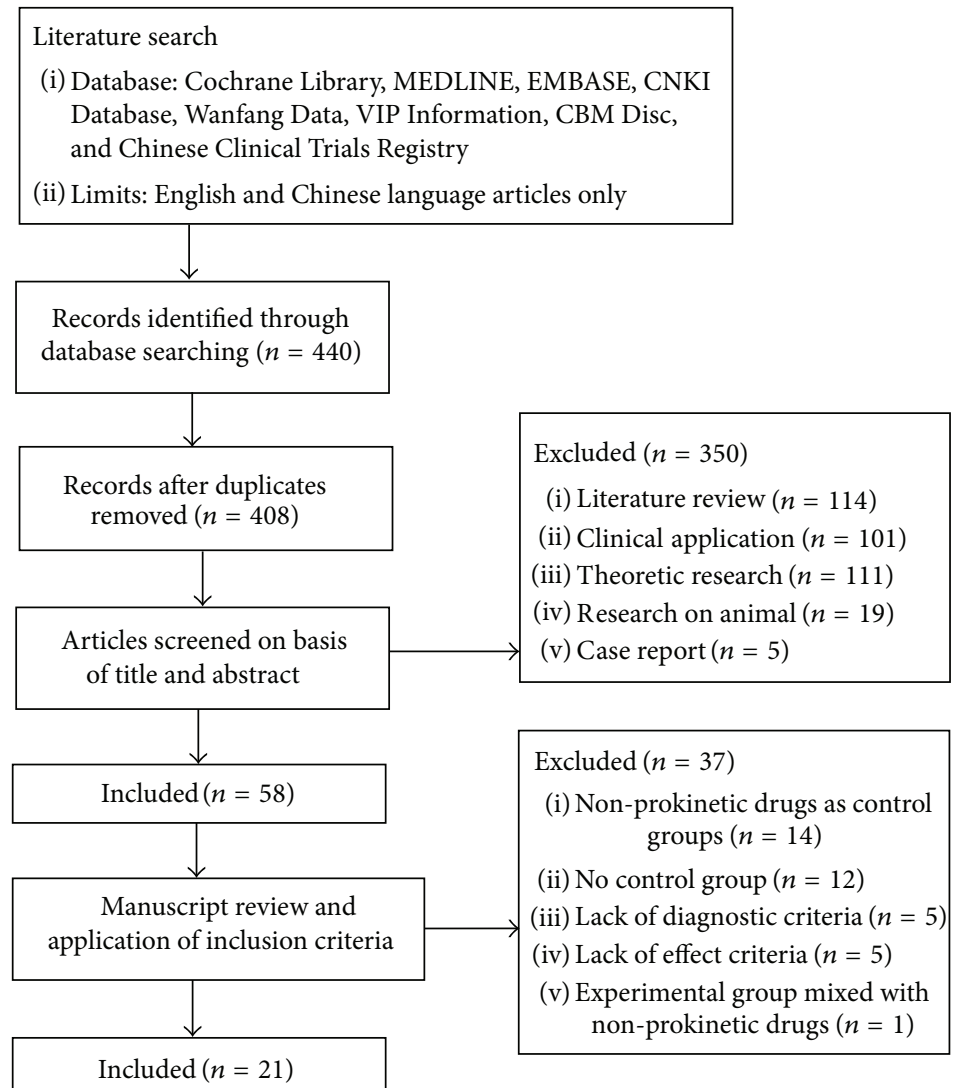

FIgURE 1: Flow diagram of selective for systematic review of MCSP for FD.

2.6. Data Items. Items extracted from each study include citations of studies, method of the trials, simple size, gender and average age of the participants, treatment duration, each group's interventions, symptom improvement index and adverse drug reaction.

2.7. Risk of Bias. Two reviewers (N. Yang and Z. Hu) independently accessed the risk of bias for each trial according to the Cochrane Handbook for Systematic Reviewers of Interventions version 5.1.0 [48]. Cochrane collaboration addressed the following seven specific domains to describe the risk of bias, including random sequence generation, allocation concealment, blinding of participants and personnel, blinding of outcome assessment, incomplete outcome data, selective outcome reporting, and other biases. Each trail was categorized as "Low risk" of bias, "High risk" of bias, or "Unclear risk" of bias. Disagreements were resolved by discussion and by adjudicated by a third reviewer (Jiang) when necessary.

2.8. Summary Measures. Our comparisons included MCSP versus prokinetic drugs and MCSP plus prokinetic drugs versus prokinetic drugs. We analyzed the main outcomes data of the trials according to Cochrane Handbook. We reported risk ratio (RR) with $95 \%$ confidence intervals (CI) for the dichotomous data, and mean differences (MD) with $95 \%$ CI for continuous data. We used Chi-square statistic to assess the heterogeneity. Fixed effect model can be appropriate when there is statistical homogeneity $\left(P>0.1, I^{2}<50 \%\right)$ among the studies, and random effect model has to be pursued when statistical heterogeneity $\left(P<0.1, I^{2}>50 \%\right)$ exists in the trials. Publication bias was assessed by the funnel plot.

\section{Results}

3.1. Study Selection. The study selection process, the reasons for excluding, and the search results at various stages were shown as a flow diagram (Figure 1) according to the planed search strategy. Successive rounds of review yielded 21 final studies, and one of those studies contained 2 RCTs [33]. The total of 22 RCTs were included, involving 1939 participants with FD. All studies were conducted in Chinese. In the trials, 13 RCTs compared MCSP versus prokinetic drugs, and 9 RCTs compared MCSP plus prokinetic drugs versus prokinetic drugs. There were no placebo controlled studies.

3.2. Study Characteristics. Of the 22 selected trials, 21 described the comparability analysis of source of participants, gender, age, and course of FD. The remaining 1 trail did not mention the information. The mean age of participants ranged from 33.9 to 56.0 years. Trial duration lasted for 3 weeks to 12 weeks. MCSP was prepared as decoction with traditional method of being boiled with water. All 


\begin{tabular}{|c|c|c|c|c|c|c|c|c|}
\hline \multirow{2}{*}{ Study or subgroup } & \multicolumn{2}{|c|}{ MCSP } & \multicolumn{2}{|c|}{ Prokinetic drugs } & \multirow[b]{2}{*}{ Weight } & \multirow{2}{*}{$\begin{array}{c}\text { Risk ratio } \\
\text { M-H, fixed, 95\% CI }\end{array}$} & \multirow{2}{*}{\multicolumn{2}{|c|}{$\begin{array}{c}\text { Risk ratio } \\
\text { M-H, fixed, 95\% CI }\end{array}$}} \\
\hline & Events & Total & Events & Total & & & & \\
\hline Gao, 2003 [32] & 98 & 104 & 47 & 60 & $14.7 \%$ & $1.20[1.04,1.39]$ & & $\rightarrow$ \\
\hline Gong, 2010 [39] & 36 & 43 & 29 & 43 & $7.2 \%$ & $1.24[0.97,1.59]$ & & - \\
\hline Hu and Zhang, 2007 [35] & 21 & 31 & 21 & 30 & $5.3 \%$ & $0.97[0.69,1.36]$ & & - \\
\hline Huang and Yuan, 2006 [34]: & 63 & 69 & 47 & 68 & $11.7 \%$ & $1.32[1.11,1.57]$ & & 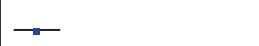 \\
\hline Jin et al., 2012 [42] & 30 & 36 & 24 & 36 & $5.9 \%$ & $1.25[0.95,1.64]$ & & \\
\hline $\mathrm{Li}, 2010[40]$ & 28 & 30 & 23 & 30 & $5.7 \%$ & $1.22[0.98,1.52]$ & & . \\
\hline G.Liang and Y. Liang, 2005 [33] & 38 & 42 & 29 & 41 & $7.3 \%$ & $1.28[1.03,1.59]$ & & —- \\
\hline Pei and Zhao, $2009[26]$ & 34 & 40 & 33 & 40 & $8.2 \%$ & $1.03[0.85,1.25]$ & & - \\
\hline Tan et al., $2010[38]$ & 31 & 36 & 23 & 35 & $5.8 \%$ & $1.31[1.00,1.72]$ & & 急 \\
\hline Zhang, $2010[41]$ & 47 & 50 & 43 & 50 & $10.6 \%$ & $1.09[0.96,1.25]$ & & - \\
\hline Zhang, $2011[27]$ & 21 & 23 & 22 & 31 & $4.6 \%$ & $1.29[0.99,1.67]$ & & - \\
\hline Zhou, 2008 [36] & 38 & 40 & 33 & 40 & $8.2 \%$ & $1.15[0.98,1.35]$ & & 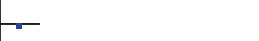 \\
\hline Zhu, 2008 [37] & 26 & 32 & 20 & 32 & $4.9 \%$ & $1.30[0.95,1.78]$ & & \\
\hline Total $(95 \% \mathrm{CI})$ & & 576 & & 536 & $100.0 \%$ & $1.20[1.13,1.27]$ & & $\bullet$ \\
\hline Total events & 511 & & 394 & & & & & \\
\hline \multicolumn{7}{|c|}{ Heterogeneity: $\chi^{2}=8.75, \mathrm{df}=12(P=0.72) ; I^{2}=0 \%$} & $\begin{array}{llllll} & 1 & 1 & 1 \\
0.5 & 0.7 & 1\end{array}$ & 1.52 \\
\hline \multicolumn{7}{|c|}{ Test for overall effect: $Z=6.15(P<0.00001)$} & Favours control & Favours experimental \\
\hline
\end{tabular}

FIgURE 2: MCSP versus prokinetic drugs; outcomes: the total effectiveness.

the interventions were taken orally. Further details of the included RCTs were presented in Table 1. Incidence of adverse reactions of 22 trials was no related reports.

3.3. Risk of Bias within Studies. Overall the studies were at high risk of bias, which were shown in Table 2. All the trials claimed randomization, but only three RCTs [33, 38] reported that random number table was used. The remaining studies failed to provide information of how randomization was carried out. No allocation concealment and blinding were described. There were not notifications of dropouts and withdraws. No intention-to-treatment analyses were presented.

\subsection{Results of Individual Studies}

3.4.1. The Total Effective Rates of MCSP versus Prokinetic Drugs for FD. Thirteen trials compared the clinical total effectiveness of MCSP versus prokinetic drugs for FD ( $n=$ $1112)$. The test for heterogeneity was insignificant statistically $\left(P=0.72, I^{2}=0 \%\right)$. Therefore, fixed effect model was used in the meta-analysis. The risk ratio for improvement of FD for MCSP treated versus prokinetic drugs treated was 1.20(95\% CI 1.13 to 1.27 ), which achieved statistically significant (see Figure 2).

3.4.2. The Total Effective Rates of MCSP Plus Prokinetic Drugs versus Prokinetic Drugs for FD. Nine studies compared the clinical total effectiveness of MCSP versus prokinetic drugs for FD $(n=827)$. The test for heterogeneity was insignificant statistically $\left(P=0.85, I^{2}=0 \%\right)$. Therefore, fixed effect model was used in the meta-analysis. MCSP plus prokinetic drugs had a greater probability of relieving the symptom of FD compared with prokinetic drugs alone ( $\mathrm{RR}=1.18,95 \%, \mathrm{CI} 1.11$ to 1.25) (see Figure 3).
3.5. Risk of Bias across Studies. Figure 4 showed the reporting bias of trails on MCSP versus prokinetic drugs for FD. Each dot represented one study. The distribution of dots on the either side of center line was asymmetrical, which meant that there was a potential reporting bias.

To avoid distinguishing chance from real asymmetry because of fewer trials with too low power according to the Cochrane Handbook, we did not use test for funnel plot to detect the reporting biases of trails on MCSP plus prokinetic drugs versus prokinetic drugs for FD.

\section{Discussion}

4.1. Summary of Evidence. With the development of new effective treatments, herbal medicines have been increasingly used in many countries especially for benign and chronic conditions such as FD $[49,50]$. Some studies showed that artichoke leaf extract [51], peppermint and caraway oil [52], MCSP [27-47], and Rikkunshito (Liu Jun Zi Tang) [53] were advocated for FD. However, there had been no systematic research to indicate that MCSP did worse or better than other medicines against FD.

FD is dyspepsia without evidence of an organic disease that is likely to explain the symptoms. There is no certain cure for it thus far. A vast number and variety of pharmacological treatment strategies was introduced to relieve the symptoms of FD. But some problems exist in allmost treatments. The efficacy of $H$. pylori eradication for FD remains controversial. Some meta-analyses concluded that $\mathrm{H}$. pylori eradication had significant advantage over placebo $[54,55]$, but there were other studies which found insufficient or no benefit existing in treating FD [56, 57]. Histamine-type 2 receptor had superiority over placebo for patients with FD in clinical trials [13], however, which were merely limited to the symptom of epigastric pain and did not apply in global dyspepsia symptoms [58]. Some prokinetic agents showed more significant 


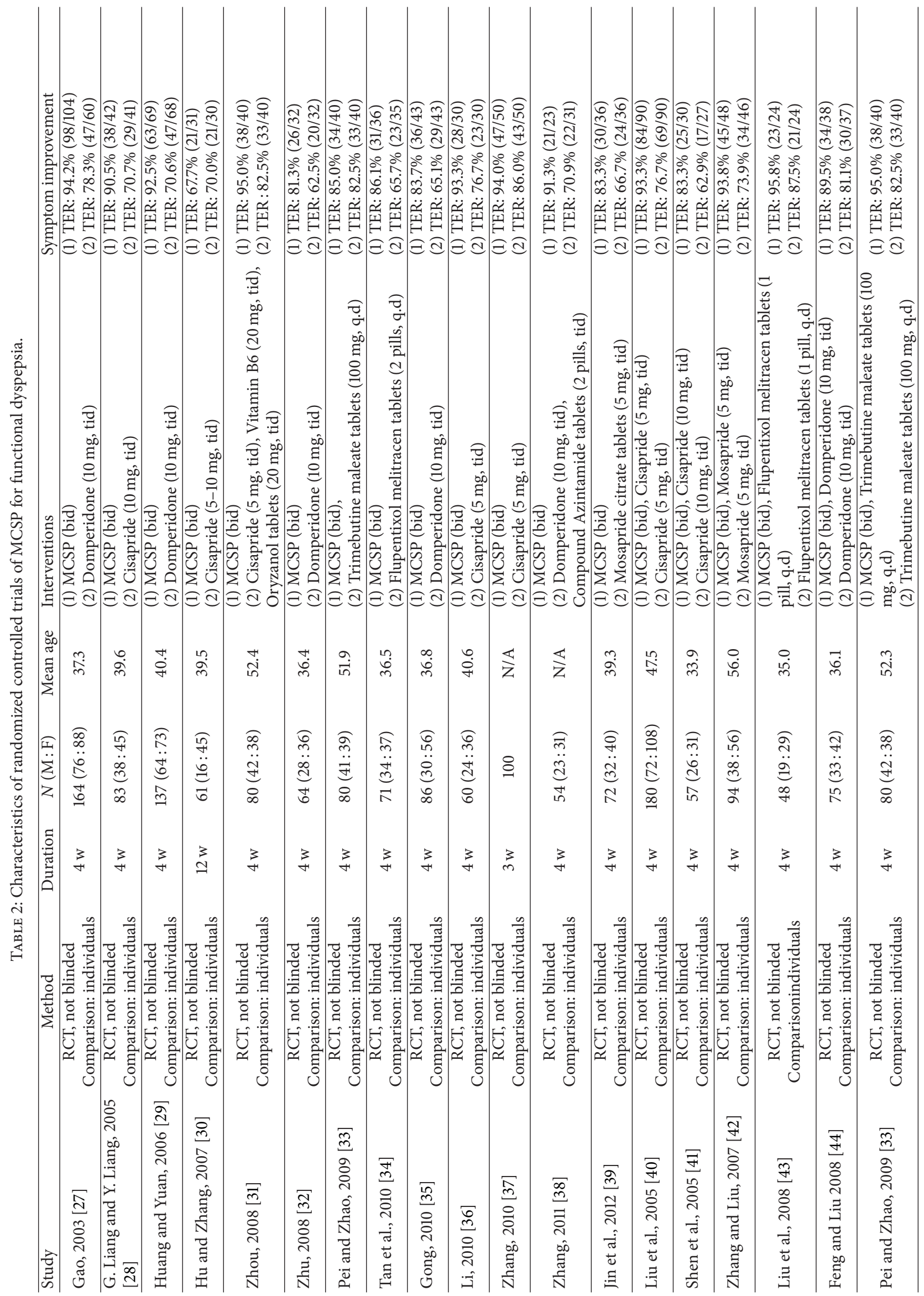




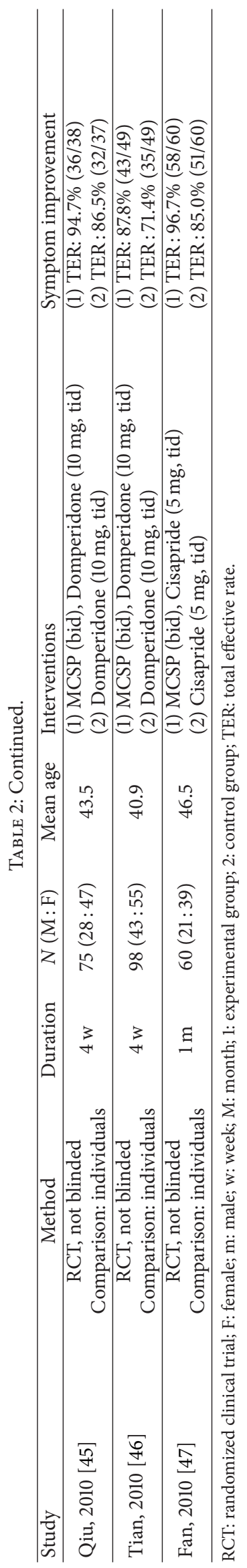




\begin{tabular}{|c|c|c|c|c|c|c|c|c|c|}
\hline \multirow[t]{2}{*}{ Study or subgroup } & \multicolumn{2}{|c|}{$\begin{array}{c}\text { MCSP + } \\
\text { prokinetic drugs }\end{array}$} & \multicolumn{2}{|c|}{ Prokinetic drugs } & \multirow[b]{2}{*}{ Weight } & \multirow{2}{*}{$\begin{array}{l}\text { Risk ratio } \\
\text { M-H, fixed, 95\% CI }\end{array}$} & \multirow{2}{*}{\multicolumn{3}{|c|}{$\begin{array}{l}\text { Risk ratio } \\
\text { M-H, fixed, } 95 \% \text { CI }\end{array}$}} \\
\hline & Events & Total & Events & Total & & & & & \\
\hline Fan, $2010[50]$ & 58 & 60 & 51 & 60 & $15.7 \%$ & $1.14[1.01,1.28]$ & & - & \\
\hline Feng and Liu, 2008 [47] & 34 & 38 & 30 & 37 & $9.4 \%$ & $1.10[0.91,1.33]$ & & . & \\
\hline Liu, 2005 [43] & 84 & 90 & 69 & 90 & $21.3 \%$ & $1.22[1.07,1.38]$ & & 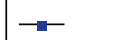 & \\
\hline Liu et al., 2008 [46] & 23 & 24 & 21 & 24 & $6.5 \%$ & $1.10[0.92,1.30]$ & & f. & \\
\hline Pei and Zhao, 2009 [26] & 38 & 40 & 33 & 40 & $10.2 \%$ & $1.15[0.98,1.35]$ & & ए & \\
\hline Qiu, 2010 [48] & 36 & 38 & 32 & 37 & $10.0 \%$ & $1.10[0.94,1.27]$ & & $f=$ & \\
\hline Shen et al., 2005 [44] & 25 & 30 & 17 & 27 & $5.5 \%$ & $1.32[0.95,1.84]$ & & & \\
\hline Tian, 2010 [49] & 43 & 49 & 35 & 49 & $10.8 \%$ & $1.23[1.00,1.51]$ & & 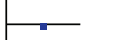 & \\
\hline Zhang and Liu, 2007 [45] & 45 & 48 & 34 & 46 & $10.7 \%$ & $1.27[1.05,1.53]$ & & - & \\
\hline Total $(95 \% \mathrm{CI})$ & & 417 & & 410 & $100.0 \%$ & $1.18[1.11,1.25]$ & & $\diamond$ & \\
\hline Total events & 386 & & 322 & & & & & & \\
\hline \multirow{2}{*}{\multicolumn{7}{|c|}{$\begin{array}{l}\text { Heterogeneity: } \chi^{2}=4.06, \mathrm{df}=8(P=0.85) ; I^{2}=0 \% \\
\text { Test for overall effect: } Z=5.68(P<0.00001)\end{array}$}} & $0.5 \quad 0.7$ & 1.5 & 2 \\
\hline & & & & & & & Favours control & Favours & s experimental \\
\hline
\end{tabular}

FIGURE 3: MCSP + prokinetic drugs versus prokinetic drugs; outcomes: the total effectiveness.



FIGURE 4: Funnel plot for MCSP versus prokinetic drugs for FD.

decrease in FD than placebo, which were widely prescribed in Canada, Mexico, and Australia like domperidone [13,59]. But some of these such as metoclopramide and cisapride were of limited use because of the central nervous system and cardiac side-effects [60, 61]. Proton pump inhibitors (PPI) have been widely evaluated in the confined patients who have ulcer-like symptoms $[62,63]$. Also antidepressants were reported to be used in treating FD, but there have been very limited data on it [64]. Thus treatment of patients with FD has been still a challenge and more effects should be made to develop new effective interventions.

MCSP is based on an ancient formula that has been clinically used in China since 1600s. Since 1990s, published clinical trials have been reporting that MCSP has good therapeutic effects on FD. Our meta-analysis truly showed that MCSP might be a benefit for the patients suffering from FD. MCSP plus prokinetic drugs appeared to be more effective than prokinetic drugs alone. Although every ingredient of preparation does help to get rid of symptoms in FD, MCSP reflects the uncertainty about the clear mechanisms. It is believed that patients who are proved to be intractable to drug therapies likely suffer psychological disturbances [65].
A study supported that Chaihu Shugan powder was effective and safe in treating depression [66]. And the present metaanalysis proved significant effectiveness of MSCP in FD, which expressed a consistency between Western and Chinese medicine.

4.2. Limitations. There are several limitations in our study. Firstly, all the included trials were at high risk of bias. All the studies were in Chinese. Of the 23 trials, only two described the method of randomization, which weakened the reliability and repeatability of the research. None of the trails provided the information about allocation concealment and blinding. No multicenter and large-scale RCTs were identified. Sample size and allocation of samples among the groups are optional. Most of the literatures had no follow-up records. Lack of intention-to-treat analysis can also lead to biased judgment of efficacy. Secondly, except one study with treatment course of 3 weeks and another with 12 weeks, the length of course in the other included trials was 4 weeks. According to the diagnostic criteria for FD, it is a chronic condition with symptoms that recur frequently over time $[16,25,26,49]$. Shortened therapeutic period of FD might impact the treatment and make it difficult to find adverse drug reactions. Moreover, included studies of MCSP did not change the monarch, minister, assistant, and guide herbal medicines of CSS's prescription, which only added several herbs, but it still needs experimental evidence to establish the effect of added ingredients. Last but not the least, MCSP in all of the included trials were prepared by boiling or decocting, which is traditional way of preparing herbal medicines in China. It contributed to no placebo used in clinical trials of traditional Chinese medicine. The composition of the same prescription, in fact, was flexible, and thus caused performance bias. Yet a research suggested that granules and decoction of 20 traditional Chinese formulas had no significant statistical difference in their effectiveness [67]. In the view of drug development, conventional forms of TCMs are beneficial for improving compliance and quality of clinical trials. 
TABLE 3: Assessment of risk of bias of included studies.

\begin{tabular}{|c|c|c|c|c|c|c|c|}
\hline Study & $\begin{array}{c}\text { Random } \\
\text { sequence } \\
\text { generation }\end{array}$ & $\begin{array}{l}\text { Allocation } \\
\text { concealment }\end{array}$ & $\begin{array}{c}\text { Blinding of } \\
\text { participants and } \\
\text { personnel }\end{array}$ & $\begin{array}{l}\text { Blinding of } \\
\text { outcome } \\
\text { assessment }\end{array}$ & $\begin{array}{l}\text { Incomplete } \\
\text { outcome data }\end{array}$ & $\begin{array}{l}\text { Selective } \\
\text { reporting }\end{array}$ & Other biases \\
\hline Gao, 2003 [27] & $\mathrm{U}$ & $\mathrm{H}$ & $\mathrm{U}$ & $\mathrm{U}$ & $\mathrm{U}$ & $\mathrm{U}$ & $\mathrm{H}$ \\
\hline G. Liang and Y. Liang, 2005 [28] & $\mathrm{U}$ & $\mathrm{H}$ & $\mathrm{U}$ & $\mathrm{U}$ & $\mathrm{U}$ & $\mathrm{U}$ & $\mathrm{H}$ \\
\hline Huang and Yuan, 2006 [29] & $\mathrm{U}$ & $\mathrm{H}$ & $\mathrm{U}$ & $\mathrm{U}$ & $\mathrm{U}$ & $\mathrm{U}$ & $\mathrm{H}$ \\
\hline Hu and Zhang, 2007 [30] & $\mathrm{U}$ & $\mathrm{H}$ & $\mathrm{U}$ & $\mathrm{U}$ & $\mathrm{U}$ & $\mathrm{U}$ & $\mathrm{H}$ \\
\hline Zhou, 2008 [31] & $\mathrm{U}$ & $\mathrm{H}$ & $\mathrm{U}$ & $\mathrm{U}$ & $\mathrm{U}$ & $\mathrm{U}$ & $\mathrm{H}$ \\
\hline Zhu, 2008 [32] & $\mathrm{U}$ & $\mathrm{H}$ & $\mathrm{U}$ & $\mathrm{U}$ & $\mathrm{U}$ & $\mathrm{U}$ & $\mathrm{H}$ \\
\hline Pei and Zhao, 2009 [33] & $\mathrm{L}$ & $\mathrm{H}$ & $\mathrm{U}$ & $\mathrm{U}$ & $\mathrm{U}$ & $\mathrm{U}$ & $\mathrm{H}$ \\
\hline Tan et al., 2010 [34] & $\mathrm{U}$ & $\mathrm{H}$ & $\mathrm{U}$ & $\mathrm{U}$ & $\mathrm{U}$ & $\mathrm{U}$ & $\mathrm{H}$ \\
\hline Gong, 2010 [35] & $\mathrm{U}$ & $\mathrm{H}$ & $\mathrm{U}$ & $\mathrm{U}$ & $\mathrm{U}$ & $\mathrm{U}$ & $\mathrm{H}$ \\
\hline $\mathrm{Li}, 2010[36]$ & $\mathrm{U}$ & $\mathrm{H}$ & $\mathrm{U}$ & $\mathrm{U}$ & $\mathrm{U}$ & $\mathrm{U}$ & $\mathrm{H}$ \\
\hline Zhang, 2010 [37] & $\mathrm{L}$ & $\mathrm{H}$ & $\mathrm{U}$ & $\mathrm{U}$ & $\mathrm{U}$ & $\mathrm{U}$ & $\mathrm{H}$ \\
\hline Zhang, 2011 [38] & $\mathrm{U}$ & $\mathrm{H}$ & $\mathrm{U}$ & $\mathrm{U}$ & $\mathrm{U}$ & $\mathrm{U}$ & $\mathrm{H}$ \\
\hline Jin et al., 2012 [39] & $\mathrm{U}$ & $\mathrm{H}$ & $\mathrm{U}$ & $\mathrm{U}$ & $\mathrm{U}$ & $\mathrm{U}$ & $\mathrm{H}$ \\
\hline Liu, 2005 [40] & $\mathrm{U}$ & $\mathrm{H}$ & $\mathrm{U}$ & $\mathrm{U}$ & $\mathrm{U}$ & $\mathrm{U}$ & $\mathrm{H}$ \\
\hline Shen et al., 2005 [41] & $\mathrm{U}$ & $\mathrm{H}$ & $\mathrm{U}$ & $\mathrm{U}$ & $\mathrm{U}$ & $\mathrm{U}$ & $\mathrm{H}$ \\
\hline Zhang and Liu, 2007 [42] & $\mathrm{U}$ & $\mathrm{H}$ & $\mathrm{U}$ & $\mathrm{U}$ & $\mathrm{U}$ & $\mathrm{U}$ & $\mathrm{H}$ \\
\hline Liu et al., 2008 [43] & $\mathrm{U}$ & $\mathrm{H}$ & $\mathrm{U}$ & $\mathrm{U}$ & $\mathrm{U}$ & $\mathrm{U}$ & $\mathrm{H}$ \\
\hline Feng and Liu 2008 [44] & $\mathrm{U}$ & $\mathrm{H}$ & $\mathrm{U}$ & $\mathrm{U}$ & $\mathrm{U}$ & $\mathrm{U}$ & $\mathrm{H}$ \\
\hline Pei and Zhao, 2009 [33] & $\mathrm{L}$ & $\mathrm{H}$ & $\mathrm{U}$ & $\mathrm{U}$ & $\mathrm{U}$ & $\mathrm{U}$ & $\mathrm{H}$ \\
\hline Qiu, 2010 [45] & $\mathrm{U}$ & $\mathrm{H}$ & $\mathrm{U}$ & $\mathrm{U}$ & $\mathrm{U}$ & $\mathrm{U}$ & $\mathrm{H}$ \\
\hline Tian, $2010[46]$ & $\mathrm{U}$ & $\mathrm{H}$ & $\mathrm{U}$ & $\mathrm{U}$ & $\mathrm{U}$ & $\mathrm{U}$ & $\mathrm{H}$ \\
\hline Fan, 2010 [47] & $\mathrm{U}$ & $\mathrm{H}$ & $\mathrm{U}$ & $\mathrm{U}$ & $\mathrm{U}$ & $\mathrm{U}$ & $\mathrm{H}$ \\
\hline
\end{tabular}

L: low risk of bias; $\mathrm{U}$ : unclear; $\mathrm{H}$ : high risk of bias.

4.3. Conclusion. The result of this review provides preliminary data suggesting that either MCSP or MCSP plus prokinetic drugs achieved statistically significant improvement of symptoms of FD than prokinetic medications alone. However, the poor methodological quality made it difficult to determine the real role of MCSP in management of FD. After all, this review produced the rational evidence for the further use, research, and development of MCSP. Further large-scale high-quality clinical trials are required for assessment (see Table 3).

\section{Conflict of Interests}

There is no conflict of interests in relation to the study discussed in the paper.

\section{References}

[1] J. Tack, R. Bisschops, and G. Sarnelli, "Pathophysiology and treatment of functional dyspepsia," Gastroenterology, vol. 127, no. 4, pp. 1239-1255, 2004.

[2] L. M. Smith, "Functional dyspepsia pathogenesis and therapeutic options-implications for management," Digestive and Liver Disease, vol. 37, no. 8, pp. 547-558, 2005.

[3] H. Miwa, J. Watari, and H. Fukui, "Current understanding of pathogenesis of functional dyspepsia," Journal of Gastroenterology and Hepatology, vol. 26, supplement 3, pp. 53-60, 2011.
[4] H. B. El-Serag and N. J. Talley, "Systematic review: the prevalence and clinical course of functional dyspepsia," Alimentary Pharmacology and Therapeutics, vol. 19, no. 6, pp. 643-654, 2004.

[5] S. Mahadeva and K. L. Goh, "Epidemiology of functional dyspepsia: a global perspective," World Journal of Gastroenterology, vol. 12, no. 17, pp. 2661-2666, 2006.

[6] H. Miwa, U. C. Ghoshal, K. M. Fock et al., "Asian consensus report on functional dyspepsia," Journal of Gastroenterology and Hepatology, vol. 23, pp. 626-641, 2011.

[7] H. B. El-Serag and N. J. Talley, "Systematic review: healthrelated quality of life in functional dyspepsia," Alimentary Pharmacology and Therapeutics, vol. 18, no. 4, pp. 387-393, 2003.

[8] G. B. Sander, L. E. Mazzoleni, and M. C. Francesconi, "Influence of organic and functional dyspepsia on work productivity: the Heroes-Dip study," Value in Health, vol. 14, pp. 126-129, 2011.

[9] R. A. Brook, N. L. Kleinman, R. S. Choung, A. K. Melkonian, J. E. Smeeding, and N. J. Talley, "Functional dyspepsia impacts absenteeism and direct and indirect costs," Clinical Gastroenterology and Hepatology, vol. 8, no. 6, pp. 498-503, 2010.

[10] K. Ogiso, A. Asakawa, H. Amitani et al., "Ghrelin: a gut hormonal basis of motility regulation and functional dyspepsia," Journal of Gastroenterology and Hepatology, vol. 26, supplement 3, pp. 67-72, 2011. 
[11] T. Oshima, F. Toyoshima, S. Nakajima et al., "Genetic factors for functional dyspepsia," Journal of Gastroenterology and Hepatology, vol. 26, supplement 3, pp. 83-87, 2011.

[12] H. D. Allescher, "Functional dyspepsia-a multicausal disease and its therapy," Phytomedicine, vol. 13, no. 1, pp. 2-11, 2006.

[13] B. E. Lacy, N. J. Talley, and G. R. Locke, "Review article: current treatment options and management of functional dyspepsia," Alimentary Pharmacology and Therapeutics, vol. 36, no. 1, pp. 3-15, 2012.

[14] X. Min and R. Zhou, Formula of Traditional Chinese Medicine, People's Medical Publishing House, Beijing, China, 2012.

[15] B. Dun and Y. Zhou, Formula of Traditional Chinese Medicine, China Press of Traditional Chinese Medicine, Beijing, China, 2006.

[16] Chinese Association of Chinese Medicine, "Functional dyspepsia traditional Chinese medicine diagnosis standard," Chinese Journal of Integrated Traditional and Western Medicine on Digestion, vol. 4, p. 1, 2002.

[17] L. F. Niu, M. Y. Qiu, T. Shi et al., "Comparative study on effects of five ancient complex prescriptions for smoothing the liver on gastrointestinal motion," Journal of Traditional Chinese Medicine, vol. 47, no. 1, pp. 56-58, 2006.

[18] X. J. Qiu, X. Huang, Z. Q. Chen et al., "Pharmacokinetic study of the prokinetic compounds meranzin hydrate and ferulic acid following oral administration of Chaihu-Shugan-San to patients with functional dyspepsia," Journal of Ethnopharmacology, vol. 137, no. 1, pp. 205-213, 2011.

[19] P. Navarroa, R. M. Giner, M. C. Recioa et al., "In vivo antiinflammatory activity of saponins from Bupleurum rotundifolium," Life Sciences, vol. 68, pp. 1199-1206, 2001.

[20] F. L. Guan and H. J. Yan, "The effect of Fructus aurantii on isolated duodenum from rabbits," Chinese Archives of Traditional Chinese Medicine, no. 2, pp. 181-182, 2002.

[21] M. Zhu, H. H. Luk, H. S. Fung et al., "Cytoprotective effects of cyperus rotundus against ethanol induced gastric ulceration in rats," Phytotherapy Research, vol. 11, no. 5, pp. 392-394, 1997.

[22] S. C. Heinrichs and Y. Taché, "Therapeutic potential of CRF receptor antagonists: a gut-brain perspective," Expert Opinion on Investigational Drugs, vol. 10, no. 4, pp. 647-659, 2001.

[23] Y. Taché, V. Martinez, L. Wang, and M. Million, "CRF1 receptor signaling pathways are involved in stress-related alterations of colonic function and viscerosensitivity: implications for irritable bowel syndrome," British Journal of Pharmacology, vol. 141, no. 8, pp. 1321-1330, 2004.

[24] F. L. Guan, R. J. Wang, and J. H. Wang, "The influence of pericarpium citri reticulatae and hesperidin on mice gastric emptying and small intestinal propulsion function," Pharmacology and Clinics of Chinese Materia Medica, vol. 18, pp. 7-9, 2002.

[25] N. J. Talley, V. Stanghellini, R. C. Heading, K. L. Koch, J. R. Malagelada, and G. N. J. Tytgat, "Functional gastroduodenal disorders," Gut, vol. 45, no. 2, pp. II37-II42, 1999.

[26] J. Tack, N. J. Talley, M. Camillerri et al., "Functional gastoduodenal disorders," Gastroenterology, vol. 130, no. 5, pp. 1466-1479, 2006.

[27] J. Gao, "The effect of modified Chaihu Shugan powder for functional dyspepsia," Chinese Journal of Current Clinical Medicine, vol. 1, no. 2, pp. 158-159, 2003.
[28] G. Liang and Y. Liang, "Treating 42 cases of functional dyspepsia with modified Chaihu Shugan powder," Journal of Guangxi Traditional Chinese Medical University, vol. 8, no. 4, pp. 18-19, 2005.

[29] B. H. Huang and H. L. Yuan, "The observations on the effects of treating 69 cases of functional dyspepsia with traditional Chinese medicines," The Chinese Medicine of China, vol. 4, no. 10, pp. 338-339, 2006.

[30] F. Hu and G. Q. Zhang, “The clinical research on treating functional dyspepsia with comprehensive treatment of traditional Chinese medicine," Shanghai Journal of Traditional Chinese Medicine, vol. 41, no. 10, pp. 37-39, 2007.

[31] Q. Y. Zhou, “The clinical observations on treating functional dyspepsia with soothing liver and regulating qi," Journal of Emergency in Traditional Chinese Medicine, vol. 17, no. 11, pp. 1541-1542, 2008.

[32] W. D. Zhu, "Treating 64 cases of functional dyspepsia with modified chaihu shugan powder," China Practical Medicine, vol. 3, no. 27, p. 79, 2008.

[33] Z. G. Pei and S. M. Zhao, "Treating 120 cases of functional dyspepsia with integrated traditional Chinese and western medicine," Chinese Community Doctors, vol. 11, no. 10, p. 98 , 2009.

[34] Z. H. Tan, B. Yang, H. S. Hu et al., "The Clinical observations on treating functional dyspepsia with Chaihu Shugan Tang," Proceeding of Clinical Medicine, vol. 19, no. 1, pp. 41-42, 2010.

[35] Z. D. Gong, "The clinical observations on treating 120 cases of functional dyspepsia with Modified Chaihu Shugan Powder," Medical Information, vol. 23, no. 6, pp. 1884-1885, 2010.

[36] H. Li, "The clinical observations on treating functional dyspepsia with soothing liver and regulating qi," Hebei Medical Journal, vol. 32, no. 18, pp. 2605-2606, 2010.

[37] G. S. Zhang, "Clinical research of treating functional dyspepsia with modified Chaihu Shugan powder," Journal of Changchun University of Traditional Chinese Medicine, vol. 26, no. 3, pp. 381$382,2010$.

[38] Y. Y. Zhang, "Classification of treatment on functional dyspepsia," Chinese Journal of Clinicians, vol. 39, no. 10, pp. 47-49, 2011.

[39] L. N. Jin, C. Gan, and L. H. He, "Treating 36 cases of syndrome of liver-stomach disharmony of functional dyspepsia with modified Chaihu Shugan powder," Jiangxi Journal of Traditional Chinese Medicine, vol. 43, no. 1, pp. 19-20, 2012.

[40] W. Y. Liu, "The clinical observations on treating functional dyspepsia with integrated traditional Chinese and western medicine," Modern Journal of Integrated Traditional Chinese and Western Medicine, vol. 14, no. 5, pp. 586-587, 2005.

[41] J. Y. Shen, L. L. Wu, and Y. F. Sun, "Treating cases of functional dyspepsia with Chaihu Shugan powder," Journal of Emergency in Traditional Chinese Medicine, vol. 14, no. 7, p. 601, 2005.

[42] W. M. Zhang and J. X. Liu, “The clinical research on treating dyskinesia functional dyspepsia with integrated traditional Chinese and western medicine," Medical Journal of Communication, vol. 21, no. 2, pp. 135-136, 2007.

[43] D. Liu, Y. Qi, X. Y. Zhai et al., "The clinical observations on syndrome of liver depression with spleen insufficiency of functional dyspepsia with modified Chaihu Shugan powder combined with Deanxit," Hubei Journal of Traditional Chinese Medicine, vol. 30, no. 8, pp. 41-42, 2008. 
[44] P. Feng and W. Z. Liu, "Treating 38 cases of functional dyspepsia with modified Chaihu Shugan powder combined with Domperidone," Shaanxi Journal of Traditional Chinese Medicine, vol. 29, no. 10, pp. 1312-1313, 2008.

[45] S. J. Qiu, “Therapeutic efficacy observation on treating functional dyspepsia with modified Chaihu Shugan powder combined with Domperidone," Information on Traditional Chinese Medicine, vol. 27, no. 4, pp. 82-83, 2010.

[46] L. Tian, "Therapeutic efficacy observation on treating functional dyspepsia with modified Chaihu Shugan powder combined with Domperidone," Chinese Journal of Primary Medicine and Pharmacy, vol. 17, no. 24, pp. 3404-3406, 2010.

[47] S. Q. Fan, "The clinical observations on treating 60 cases of functional dyspepsia with integrated traditional Chinese and western medicine," Journal of Shanxi Medical College for Continuing Education, vol. 20, no. 4, pp. 58-59, 2010.

[48] J. P. T. Higgins and S. Green, Cochrane Handbook For Systematic Reviews of Interventions (Version 5. 1. 0), The Cochrane Collaboration, 2011, http://www.cochrane-handbook.org/.

[49] A. Madischa, G. Holtmannb, G. Mayrc et al., "Treatment of functional dyspepsia with a herbal preparation: a double-blind, randomized, placebo-controlled, multicenter trial," Digestion, vol. 69, pp. 45-52, 2004.

[50] J. T. Coon and E. Ernst, "Systematic review: herbal medicinal products for non-ulcer dyspepsia," Alimentary Pharmacology and Therapeutics, vol. 16, no. 10, pp. 1689-1699, 2002.

[51] G. Holtmann, B. Adam, S. Haag, W. Collet, E. Grünewald, and T. Windeck, "Efficacy of artichoke leaf extract in the treatment of patients with functional dyspepsia: a six-week placebocontrolled, double-blind, multicentre trial," Alimentary Pharmacology and Therapeutics, vol. 18, no. 11-12, pp. 1099-1105, 2003.

[52] B. May, S. Köhler, and B. Schneider, "Efficacy and tolerability of a fixed combination of peppermint oil and caraway oil in patients suffering from functional dyspepsia," Alimentary Pharmacology and Therapeutics, vol. 14, no. 12, pp. 1671-1677, 2000.

[53] H. Kusunoki, K. Haruma, J. Hata et al., "Efficacy of Rikkunshito, a traditional Japanese medicine (Kampo), in treating functional dyspepsia," Internal Medicine, vol. 49, no. 20, pp. 2195-2202, 2010.

[54] P. Moayyedi, S. Soo, J. Deeks et al., "Eradication of Helicobacter pylori for non-ulcer dyspepsia," Cochrane Database of Systematic Reviews, vol. 1, Article ID CD002096, 2003.

[55] R. Liisa Jaakkimainen, E. Boyle, and F. Tudiver, "Is Helicobacter pylori associated with non-ulcer dyspepsia and will eradication improve symptoms? A meta-analysis," British Medical Journal, vol. 319, no. 7216, pp. 1040-1044, 1999.

[56] L. Laine, P. Schoenfeld, and M. B. Fennerty, “Therapy for Helicobacter pylori in patients with nonulcer dyspepsia: a metaanalysis of randomized, controlled trials," Annals of Internal Medicine, vol. 134, no. 5, pp. 361-369, 2001.

[57] J. Danesh and R. E. Pounder, "Eradication of Helicobacter pylori and non-ulcer dyspepsia," The Lancet, vol. 355, no. 9206, pp. 766-767, 2000.

[58] H. A. Redstone, N. Barrowman, and S. J. O. van Veldhuyzen Zanten, "H2-receptor antagonists in the treatment of functional (nonulcer) dyspepsia: a meta-analysis of randomized controlled clinical trials," Alimentary Pharmacology and Therapeutics, vol. 15, no. 9, pp. 1291-1299, 2001.

[59] N. J. Talley and R. S. Choung, "Whither dyspepsia? A historical perspective of functional dyspepsia, and concepts of pathogenesis and therapy in 2009," Journal of Gastroenterology and Hepatology, vol. 24, supplement 3, pp. S20-S28, 2009.

[60] N. J. Talley, N. B. Vakil, and P. Moayyedi, "American gastroenterological association technical review on the evaluation of dyspepsia," Gastroenterology, vol. 129, no. 5, pp. 1756-1780, 2005.

[61] P. Moayyedi, S. Soo, J. Deeks, B. Delaney, M. Innes, and D. Forman, "Pharmacological interventions for non-ulcer dyspepsia," Cochrane Database of Systematic Reviews, no. 4, Article ID CD001960, 2006.

[62] V. Rensburg, P. Berghöfer, R. Enns et al., "Efficacy and safety of pantoprazole $20 \mathrm{mg}$ once daily treatment in patients with ulcer-like functional dyspepsia," Current Medical Research and Opinion, vol. 24, pp. 2009-2018, 2008.

[63] W. H. Wang, J. Q. Huang, G. F. Zheng et al., "Effects of proton pump inhibitors on functional dyspepsia:a meta-analysis of randomized placebo-controlled trials," Clinical Gastroenterology and Hepatology, vol. 5, no. 2, pp. 172-178, 2007.

[64] N. J. Talley, L. Herrick, and G. R. Locke, "Editorial: antidepressants in functional dyspepsia," Expert Review of Gastroenterology and Hepatology, vol. 4, no. 1, pp. 5-8, 2010.

[65] G. Holtmann, S. U. Kutscher, S. Haag et al., "Clinical presentation and personality factors are predictors of the response to treatment in patients with functional dyspepsia: a randomized, double-blind placebo-controlled crossover study," Digestive Diseases and Sciences, vol. 49, no. 4, pp. 672-679, 2004.

[66] Y. Wang, R. Fan, and X. Huang, "Meta-analysis of the clinical effectiveness of traditional Chinese medicine formula ChaihuShugan-San in depression," Journal of Ethnophamacology, vol. 141, no. 2, pp. 571-577, 2012.

[67] L. Hui, L. Qing, A. Flower et al., "Comparison of effectiveness and safety between granules and decoction of Chinese herbal medicine: a systematic review of randomized clinical trials," Journal of Ethnopharmacology, vol. 140, no. 3, pp. 555-567, 2012. 


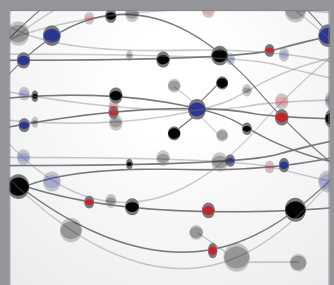

The Scientific World Journal


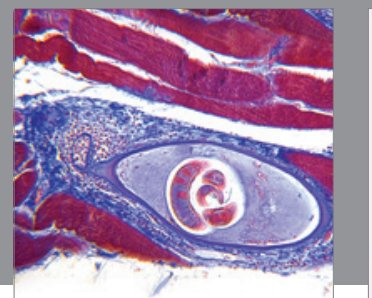

Gastroenterology

Research and Practice
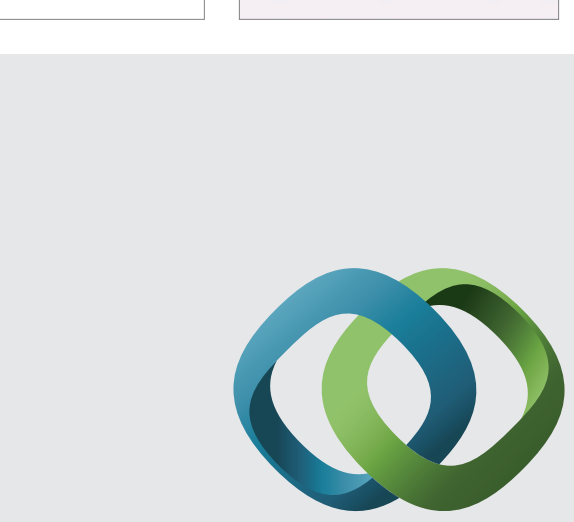

\section{Hindawi}

Submit your manuscripts at

http://www.hindawi.com
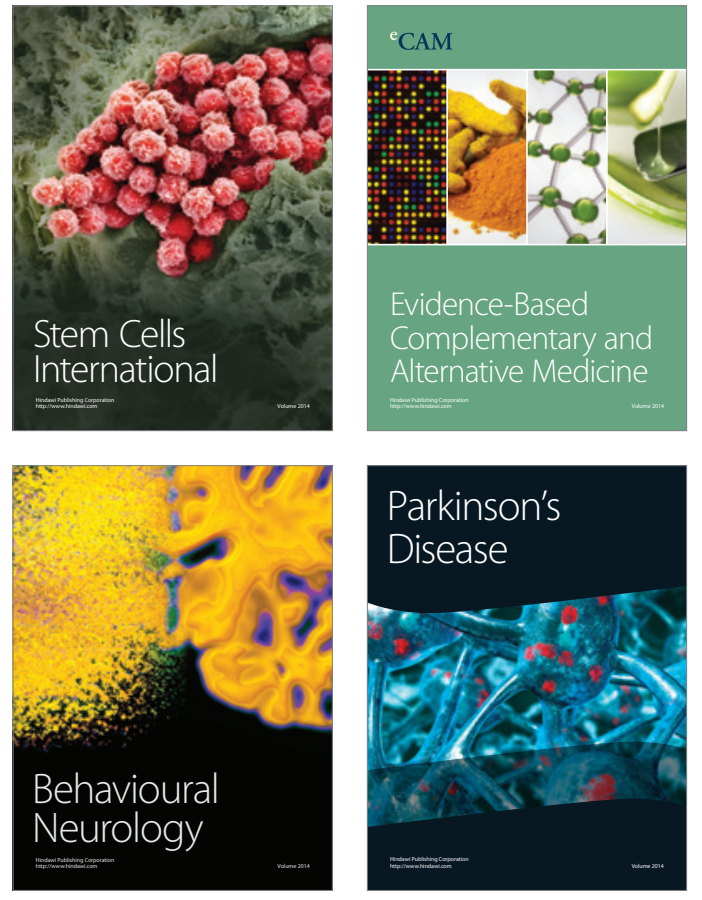
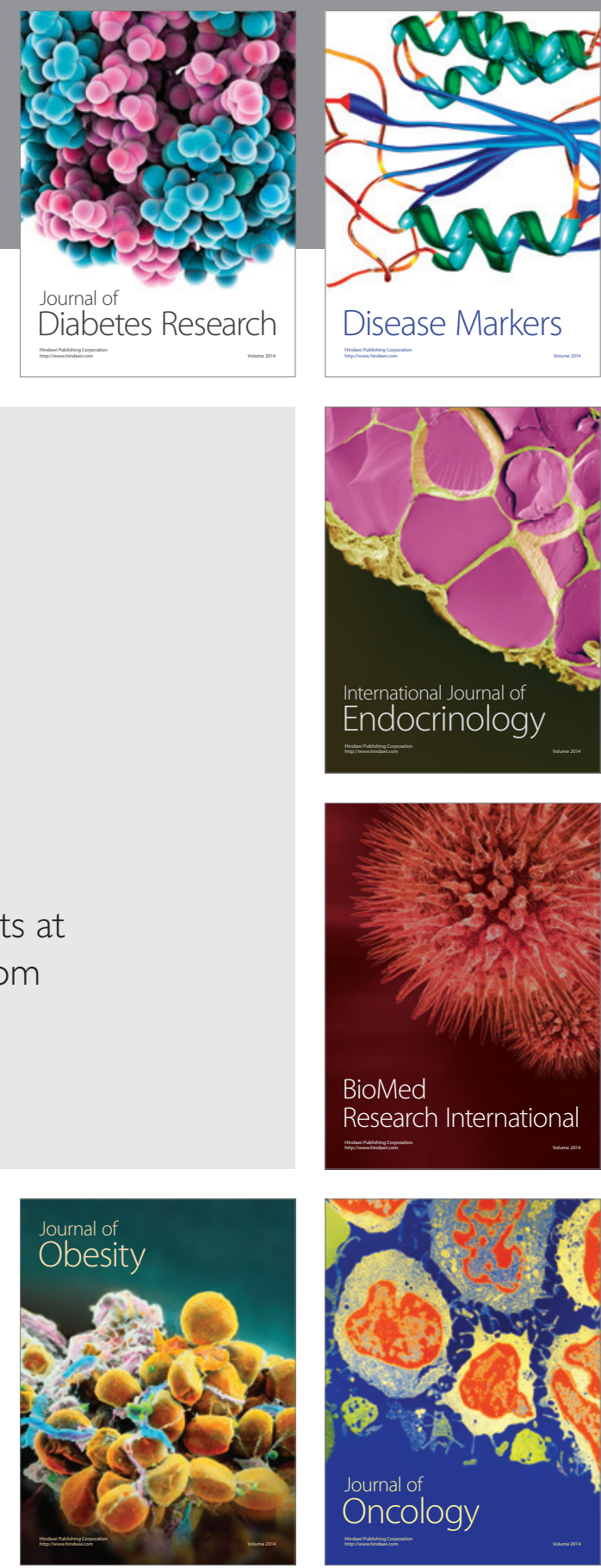

Disease Markers
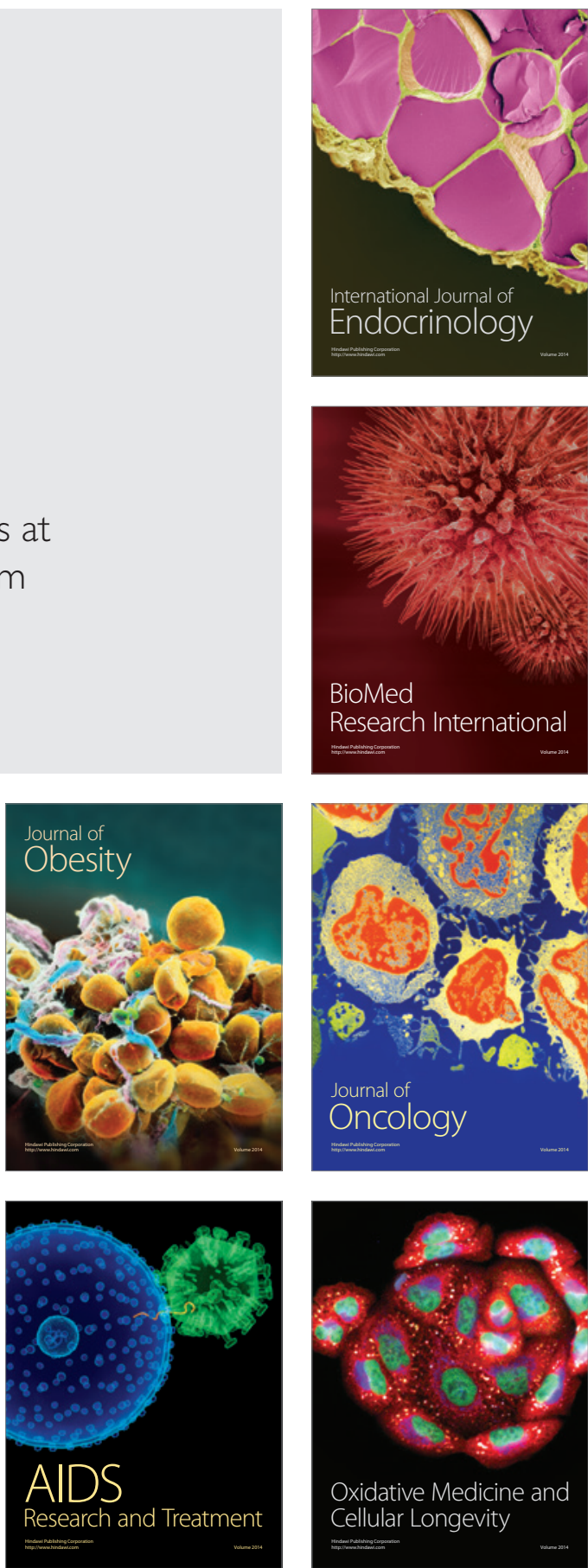